\title{
MEASUREMENT OF FIRN MOTION BY A MAGNETIC PROSPECTING METHOD
}

\author{
By L. Lliboutry \\ (Faculté des Sciences, Grenoble, France)
}

\begin{abstract}
ABSTRAGt. The compaction and flow within néve can be studied by means of magnetized steel tubes buried in vertical pits. The locations of the tubes, their distances from the surface, down to a depth of $10 \mathrm{~m}$., and their angles with the vertical can be determined from measurements made with a B.M.Z. magnetometer.

Résumé. On peut suivre le tassement et le mouvement du névé à l'aide de tubes d'acier aimanté enfouis dans les trous verticaux. Des mesures avec un magnétomètre B.M.Z. permettent en effet de déterminer très simplement le lieu et la profondeur a laquelle se trouvent ces tubes, ainsi que leur angle avec la verticale, jusqu'à une dizaine de mètres de profondeur.
\end{abstract}

Zusammenfassung. Die Verdichtung und Strömung innerhalb des Firns kann mit Hilfe von magnetisierten Stahlrohren studiert werden, die in vertikale Löcher eingelassen werden. Die Lage der Rohre, ihr Abstand von der Oberfläche bis hinab zu einer Tiefe von $10 \mathrm{~m}$ und ihre Neigungswinkel können durch Messungen mit einem B.M.Z. Magnetometer bestimmt werden.

To obtain a comprehensive view of glacier nourishment, the compaction and flow of the firn must be measured, among other studies. If firn flow is not taken into account, velocity measurements in the underlying glacier, and hence the estimation of glacier thickness and the rate of ice flow from the collecting basin, would be erroneous. The firn flow is important, although this diminishes with the elapse of time since its deposition. ${ }^{\mathrm{I}}$ Moreover, the firn flow follows the local surface slope, whereas the glacier flow follows the general surface slope of the area.

The field chosen for this particular experiment was the upper part of the Vallée Blanche, one of the tributaries of the Mer de Glace, in the Mont-Blanc Massif. It is gently sloping névé, $\mathrm{I} \mathrm{km.}{ }^{2}$ in area and located at an altitude of about $3,500 \mathrm{~m}$., at the foot of the Laboratoire de l'Aiguille du Midi. The net amount of snow which collects there in winter is about 4 or $5 \mathrm{~m}$., and only half of this melted in the Summer of 1959 , an exceptionally sunny one. A study of firn motion by means of $8 \mathrm{~m}$. high stakes which continually emerge from one year to another is impracticable, for a vertical line in the névé will become a very much incurved line by the end of a year. In order to make accurate measurements it would be necessary to bury markers at a depth of $10 \mathrm{~m}$. and seek them afterwards by digging pits. Such digging can be avoided by burying magnets in the névé and seeking them afterwards by magnetic prospecting. This method facilitates the measurements, which can then be made at many points on the névé.

The magnets, which will be lost within a few years, are tubes made of ordinary steel. Their diameters range from 6 to $7.5 \mathrm{~cm}$. and their lengths are about $2 \mathrm{~m}$. They are blind at both ends so that their total density is not greatly different from that of the néve, thus avoiding differential movement. The tubes were buried in Autumn 1959. The vertical holes were drilled with a SIPRE coring auger which had been loaned to us by the French Antarctic Sub-Committee of the I.G.Y. On this occasion the holes were drilled to a depth of $5 \mathrm{~m}$. in order to determine the sensitivity of the method as early as the following Spring. Messrs. Lesbre and Luscan, who were responsible for this work, had previously determined the magnetic moments, $M$, with a "Grassot" fluxmeter constructed by the Compagnie des Compteurs de Montrouge.

In May 1960 the previous positions of the magnets were determined by triangulation, by simultaneous observations from two theodolites set at the ends of a $79 \mathrm{~m}$. base near the laboratory. The area was prospected rapidly from these points with a magnetic balance for $Z$ (B.M.Z. of the Danish Meteorologic Institute), a standard instrument used during the 
I.G.Y., carried on a light non-magnetic sledge. The point about $20 \mathrm{~m}$. down-flow, where the anomaly on the vertical component, $Z$, of the magnetic field was at its maximum, could then be determined. A magnetic profile was drawn along the steepest local slope on both sides of this point for some $40 \mathrm{~m}$.

The slope is uniform and gentle along this profile, so that there could be confusion between the anomaly, $\Delta Z$, and the component of the field created by the magnet along $0 z$, which is taken perpendicular to the surface. The magnet is considered as a doublet situated at $o$ in the xoz plane, its angle with the vertical being $\alpha$. If $\alpha$ is taken as positive when the upper end of the magnet points down-glacier or its lower end points up-glacier (the general case), then:

$$
\tan \alpha=t \text { and } \frac{x}{z}=\xi
$$

The anomaly along the profile $(y=0, z=$ constant $)$ is:

$$
\Delta Z=\frac{2 M}{Z^{3}} \frac{\mathrm{I}-\frac{\xi^{2}}{2}+\frac{3 \xi}{2} t}{\left(\mathrm{I}+t^{2}\right)^{\mathrm{I} / 2}\left(\mathrm{I}+\xi^{2}\right)^{5 / 2}}
$$

In Figure $\mathrm{I}$ the curves for $t=0,0.5, \mathrm{I}, 2$ and $\infty$ have been translated in order to make the maxima coincide, as these maxima are the points directly accessible to measurements.

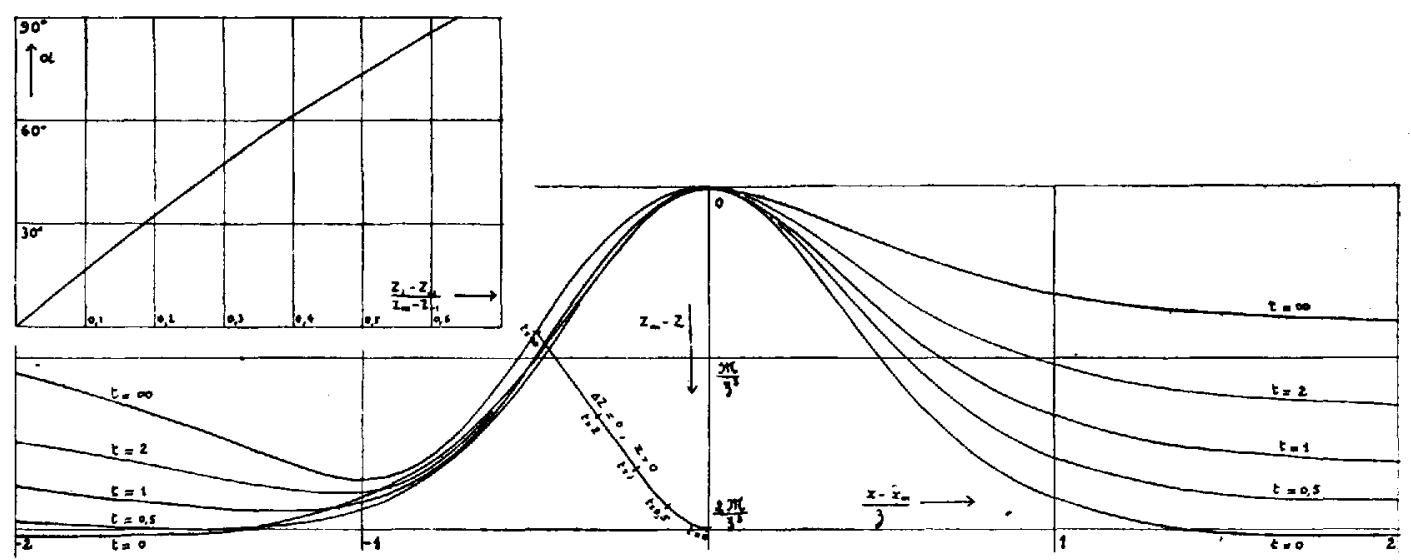

Fig. I

If the abscissa of the maximum is $x_{m}$, it can be seen that for $-z<x-x_{m}<0$, the anomaly $\Delta Z$ is almost independent of the inclination, $t=\tan \alpha$, of the magnet. Then the depth of the magnet, $z$, can be computed to within an error of 2 per cent. by:

$$
Z_{m}-Z_{-1}=\frac{\mathrm{I} \cdot 82 M}{z^{3}}
$$

where $Z_{m}=$ the vertical field where the anomaly is a maximum, and $Z_{-x}=$ the vertical field at a distance from the maximum, upwards, and more or less equal to $z$. As the anomaly there is near a maximum, this value is not very sensitive to any error in $z$.

The inclination, $\alpha$, can then be determined by the degree of the anomaly down-glacier. For this purpose the field at a distance from the maximum equal to $z$, down-glacier, is denoted by $\bar{Z}_{\mathrm{I}}$. The following ratio can then be computed:

$$
\frac{Z_{I}-Z_{-1}}{Z_{m}-Z_{-1}}=f(\alpha)
$$

This curve is also shown in Figure $I$ and it is nearly a straight line. 
Since an approximate value of $\alpha$ is known, the exact value of $z$ can be determined; from this a more accurate value of $\alpha$ can be calculated.

The abscissa of the magnet is then given by the curve $(\Delta Z=0, x=0)$ in Figure $I$. For instance, the horizontal distance between the maximum of the anomaly and the magnet is $o$ if it stands vertically and $-z / 2$ if it lies horizontally.

If measurements are taken to 5 gammas (a common performance with a B.M.Z.), the magnetic moments are of the order $0.5 \times 10^{6}$ c.g.s. e.m.u. and the magnets are buried at a depth of $8 \mathrm{~m}$., then $z$ can be determined to $5 \mathrm{~cm} ., \alpha$ to $4^{\circ}$ and the abscissa of the magnet to $0.5 \mathrm{~m}$.

Thus we have a cheap and rapid method of studying firn motion down to a depth of Io $\mathrm{m}$. When studying a natural variable which fluctuates widely from one point to another, such a method is preferable to any other which would be more accurate, but more time consuming or more expensive, and thus impossible to use at many points simultaneously.

MS. received 22 fuly $r g 60$

\section{REFERENCE}

1. Miller, M. M. Phenomena associated with the deformation of a glacier bore-hole. Union Géodésique et Géophysique Internationale, Association Internationale d'Hydrologie Scientifique, Assemblée générale de Toronto, 1957, Tom. 4, [1958], p. 437-52. 